\title{
Towards a Code of Cyberethics
}

\author{
Udo Averweg \\ eThekwini Municipality and University of KwaZulu-Natal < averwegu@durban.gov.za >
}

\begin{abstract}
Ethics and accountability are cornerstones of public management. One of the ways in which ethical standards in the public service can be promoted is by developing a Code of Conduct that sets a standard of behaviour to be followed. The diversity of information and communication technologies (ICT) and increased use of ICT have created a variety of ethical issues. In this paper, the process for formulating a Code of Cyberethics for eThekwini Municipality in South Africa is described. The development of such a code will also ensure service delivery that responds to citizens' needs and improves the communication process with citizens.
\end{abstract}

\section{Introduction}

Ethics and accountability are cornerstones of public management (Mafunisa, 2000). Ethics is a branch of philosophy that deals with what is considered to be right and wrong. Ethics is the study of what is good or right for human beings (Hoffman \& Moore, 1990). One of the ways in which high ethical standards in the public service can be promoted is by developing Codes of Conduct that set a standard of behaviour to be followed within specific occupational categories (du Plessis, 2004). One occupational category is Information and Communication Technologies (ICT) work, including jobs related to the social appropriation of ICT in a local municipality.

The structure of this paper is as follows. Ethical theories with a focus on principle-based theory are introduced. The concepts of cybertechnology and cyberethics are discussed. The eThekwini Municipality environment in South Africa as a setting for the formulation of a Code of Cyberethics is described. Some concluding remarks are then given.

\section{Ethical Theories}

In today's complex environment, it is not always clear what is "right" and what is "wrong". Right actions are those that it is useful to praise, wrong actions are those that it is useful to blame (Russell, 1971). The right ethical answer may or may not be the answer that is prescribed by law; in fact, depending on the ethical assumptions made, the two may on occasion be in conflict (Smith, 2002). The challenge is to make essential ethical decision-making explicit so as to improve it (Sternberg, 1994). Although tailor-made Codes of Conduct will not be sufficient in themselves, they should be viewed as an integral part of integrating ethics management within the broader public management environment (du Plessis, 2004). Many organisations develop their own codes of ethics. A code of ethics is a collection of principles intended as a guide for employees in an organisation. Andrews (1988) defines "ethics" as standards that guide the behaviour and actions of public officials in public institutions and which may be referred to as "moral laws". The diversity of ICT applications and the increased use of ICT have created a variety of ethical issues. Ethical theories are theories about justifying our moral actions (Rossouw, 1994). They propose appropriate reasoning on which our moral decisions should be based.

A broad range of ethical theories has been developed to identify how we should determine what is actually good not only for one's self but also for others. Ethical theories attempt to answer the question, why be ethical? Some key ethical theories were formulated by Immanuel Kant. One of the basic tenets of Kantian Ethics is based on the idea that duty is fundamental and is "principle-based". Principle-based theory is one that bases the value of an action on the nature of the action itself. One advantage of duty ethics is that it gives a powerful and clear framework for stating codes of ethics. Another advantage is that it is impartial: the same rules apply to all 
persons. It is argued that principle-based theory should therefore serve as foundation for formulating a Code of Cyberethics.

\section{Principle-based theory}

Principle-based theory emphasizes that moral actions should be in accordance with a pre-established rule or rules. The expectation is that progress toward an objective standard of moral behaviour will be made if people base their actions on fixed rules. It is argued by the author that a Code of Cyberethics is an example of fixed rules.

The best-known proponent of a rule-based theory is Immanuel Kant (1724 - 1804). He was convinced that all rational-thinking people should be able and willing to subscribe to a basic rule that should govern all moral behaviour. Kant was convinced that such a strategy would improve the quality of moral decisions and enhance the respect that people pay each other (Rossouw, 1994). Advantages of this approach are that it:

- $\quad$ Respects the rights and interests of all persons and not only those in the majority;

- Encourages consistency and thus integrity in moral behaviour; and

- $\quad$ Provides for the obligations that we have towards other persons (for example, ICT software developers) in our respective social roles.

Some of the problems associated with this approach are that:

- Too strong a focus on rules may lead to a dogmatic approach that does not pay due attention to the consequences of actions;

- It offers no solution for those situations where two rules may come into conflict with each other; and

- Contrary to Kant's expectation, all rational-thinking people do not always concur on the same rules for moral behaviour. For example, in the ICT domain there may be disagreement as to whether one may ethically distribute copies of downloaded music from the Internet.

This lack of consensus opens the question on whose set of rules (such as a Code of Cyberethics in the cybertechnology arena) should be accepted and who should play the role of referee in deciding this question.

\section{Cyberethics}

Some researchers use the term "computer ethics" to describe the field that examines moral ethics pertaining to ICT (see for example, Gotterbarn, 1991; Johnson, 2001). With specific concerns about ethical issues involved in the Internet, other researchers use the term "Internet ethics" (Langford, 2000). It is felt by the author that ethical issues are not limited to the Internet or to computing machines as they also include privately owned computer networks and ICT. Hence for the purposes of this paper, the relatively new term "cyberethics" (Spinello, 2003, Tavani, 2004) is used to capture some of the wide range of moral issues involving cybertechnology.

It is proposed that cyberethics is a more accurate term for two reasons:

- The term computer ethics can connote ethical issues construed as pertaining to stand-alone or unconnected computers. However, with the advent of networked systems, a computer system may nowadays be thought of more accurately as a new kind of medium as opposed to a machine; and

- The term computer ethics may suggest a field of study that is concerned exclusively with ethical issues involving ICT professionals. The field of cyberethics is not linked to an analysis of moral issues that affect only these professionals (Tavani, 2004).

\section{Codes of ethics}

Hanekom \& Thornhill (1987) define a code of ethics as a set of rules made by a higher authority for a specific homogeneous group of officials, with a view to eliciting from them a specific behaviour under specific conditions. The value of codes is often overstated: on their own and unaccompanied by the appropriate habits, expectations and sanctions, codes of conduct are of little value (Sternberg, 1994). Furthermore the appropriate basis for codes of conduct is often equally misunderstood: what legitimises codes are not stakeholder consent 
but ethical content. Nevertheless, codes of conduct (such as a proposed Code of Cyberethics for eThekwini Municipality) can be extremely useful.

By explicitly communicating corporate purposes regarding controversial matters (such as copying someone else's software for personal use) and by clarifying which stakeholder expectations are legitimate, codes of conduct can eliminate ignorance as an excuse. Furthermore, they can be an effective tool for sharpening business accountability and improving corporate governance. Also, instilling a sense of professionalism in public officials will promote a respect for public service goals, core values and codes of conduct (Mafunisa, 2000). An information governance framework should contain measurable and strategic goals that will be beneficial for the provider and citizens and promote ethical standards. Professionals in the public service are custodians of the public trust and therefore have to be worthy of that trust (du Plessis, 2004).

Codes must be properly structured and should not solely reflect the prevailing values or culture of the organisation (such as eThekwini Municipality). For example, when the existing culture is less than perfect, enshrining it in a code merely reinforces bad practice - what it prescribes must be better than the existing norm. A code of conduct is not a survey of employees' ethical attitudes (Sternberg, 1994). It is meant to express, for example, eThekwini Municipality's fundamental aims and values. It is for the eThekwini Municipality to state what those aims and values are. A code of conduct sets out what constitutes ethical conduct for the business (such as cybertechnology) and its validity depends on the correctness of the values and principles it expresses not on employee agreement.

A policy may not please everyone but if principles other than those of personal interest are applied, at least "moral logic" can be followed and accepted, if not actually agreed with (Evans, cited in Mafunisa, 2000). Ideally, stakeholders will share the values embodied in the code. However, if they do not, it is the stakeholders (eThekwini Municipality employees) and not the code which should be changed. One needs to take "into consideration that citizens' expectations of government are to a large extent influenced by their interaction with municipalities, mainly because of the types of services that are rendered" (du Plessis, 2004). If public officials do not have a code of ethics with reference to which their actions are led, directed and guided, the result would probably be as catastrophic as when power and authority are delegated without enforcing accountability (Andrews, 1988). Such are the challenges for the formulation of a Code of Cyberethics for eThekwini Municipality.

Codes of ethics involve the formalisation of some rules and expected actions (Turban et al., 2004). Violation of a code of ethics may lead to the termination of employment. Codes of ethics are valuable for raising awareness of ethical issues and clarifying what is acceptable behaviour in a variety of circumstances. In the case of eThekwini Municipality, an ICT Code of Cyberethics does not exist and the formulation of one is required to prevent Internet abuse and misuse by employees. Organisations are increasingly faced with serious legal and liability issues stemming from wrongful use of software by their employees (Straub \& Collins, 1990).

The acceptance of a Code of Conduct is a central part of being a professional (du Plessis, 2004). Codes of ethics have limitations because they generalise acceptable behaviour despite the variations in social and ethical values that may exist in different communities. For example, it would be arrogant to impose on eThekwini Municipality employees the ethical ICT standards developed in and appropriate for Hong Kong, or indeed to do the reverse. However, such impositions do appear to be commonplace and they tend to lead to outright rejection (rather than to higher ethical standards, which presumably is the intention).

\section{Employee involvement}

The process of formulating a formal code of conduct can be an effective mechanism for disseminating public service values if it is an inclusive one (Mafunisa, 2000). Employee involvement can be valuable (Sternberg, 1994). It is not supposed to be a top-down process (Mafunisa, 2000). A code will be most effective if it addresses matters which actually cause concern. Sternberg (1994) suggests that it is sensible to consult stakeholders (especially employees) to determine what situations are genuinely problematic. This approach was undertaken by the author and informal discussions held with colleagues at eThekwini Municipality. Some of the cybertechnology and related concerns raised by the author's colleagues are reflected in Table 1.

Table 1. Cybertechnology and related concerns raised by author's colleagues at eThekwini Municipality

\begin{tabular}{|l|l|}
\hline No & Concern raised \\
\hline 1 & May I copy someone else's software for my own personal use and distribute it? \\
\hline 2 & May I download music/video from the Internet for personal use and distribute it?
\end{tabular}




\begin{tabular}{|r|l|}
\hline 3 & May I access private and confidential information without consent and distribute it? \\
\hline 4 & May I access other's desktops or laptops without consent? \\
\hline 5 & $\begin{array}{l}\text { May I take programs that I have created for eThekwini Municipality and keep them for personal } \\
\text { use or use them at another employer? }\end{array}$ \\
\hline
\end{tabular}

Consultation can provide useful information about the stringency (or laxity) of employees' ethical standards and the degree of ethical diversity prevailing in eThekwini Municipality's heterogenous workforce. Cultural diversity needs to be acknowledged, as well. Furthermore, making eThekwini Municipality employees part of the code-making process may improve compliance with the Code of Cyberethics since employees may feel that they have had a role in formulating it and thus are more likely to understand the code and observe its strictures. Research into why so many Codes "die" indicates that many things can go wrong in the process of institutionalising codes (du Plessis, 2004). These mistakes can include the way the Code was developed, written, distributed and enacted.

Once the Code of Cyberethetics has been formulated and adopted by the eThekwini Municipality Strategic Management Team 1 (Stratman), the document should form part of the City Manager's Standing Orders. Publishing a formal code serves as an explicit signal of eThekwini Municipality's commitment to ethical business conduct. By proclamation and endorsing the values it proclaims, it must be made clear that the Code will be enforced and also that the team itself considers themselves to be bound by it. To be worthy of respect, the adopted Code of Cyberethics must apply and be seen to apply to every employee in eThekwini Municipality.

\section{Intellectual property}

Intellectual property is the intangible property created by individuals or organisations. To varying degrees in different countries, intellectual property is protected under laws relating to copyright, trademarks, patents and trade secrets. Software piracy, the unauthorised copying of computer software, is widespread in many organisations today (Lending \& Slaughter, 2000). From the perspective of managers in organisations, software piracy means the threat of costly litigation on the one hand, balanced against the reduced expense for additional software if unauthorised copies are used.

The topic of intellectual property rights (IPR) is seen to be important since it relates to the fundamental right to private property - especially property that represents the fruits of one's endeavours (see, for example, Locke, 1964). IPR protects the way ideas are expressed but not the ideas themselves (Turban et al., 2004). IPR may be seen as a mechanism for protecting the creative works of individual people and organisations. However, this is problematic in societies that place less value on individual freedom and more on social order. Steidlmeier (1993) notes that in many developing countries, "individual claims on intellectual property are subordinated to more fundamental claims of social well-being". In these countries (including South Africa), the welfare of society is considered to be more important than that of any individual.

Much of the IPR discussion relates to the debate about rights and duties. Software developers demand the right of stringent legal protection for the fruits of their labour and compensation for resources expended in software development. Consequently consumers are then deemed to have a duty to pay for that software (whether it is in code, music, video or other digitised forms) and to respect the intellectual property by not stealing (copying or downloading) it, for example from the Internet.

\section{Data and Information Privacy}

The notion of privacy has become one of the most contentious issues of the global information age due to the ability of computers to perform actions previously impractical or impossible. Agranoff (1993) defines (data) privacy as the "claim of individuals, groups or institutions to determine for themselves when, and to what extent, information about them is communicated to others". Charlesworth \& Sewry (2002) note that privacy includes considerations of the conflicts between society's right to know and individual's right to privacy. Nevertheless the right to privacy is not absolute. It varies considerably in different cultures, as it has to be balanced by society's right to know.

1 Comprises Deputy City Managers, Deputy Heads and Heads of clusters and departments in eThekwini Municipality. 
One of the most detailed sets of data privacy principles comes from the Privacy Commissioner's Office for Personal Data (PCOPD) in Hong Kong, promulgated in 1996. A summary of the six PCOPD data protection principles is reflected in Table 2 .

Table 2. Summary of six data protection principles from the Office of the Privacy Commissioner's Office for Personal Data, Hong Kong (Source: Retrieved on 21 October, 2005 from http://www.pco.org.hk )

\begin{tabular}{|c|c|c|}
\hline No & Narrative & Associated Explanatory Text \\
\hline 1 & $\begin{array}{l}\text { Purpose and manner of } \\
\text { collection }\end{array}$ & $\begin{array}{c}\text { Data should be collected in a fair and lawful manner. Data users } \\
\text { should explain to data subjects what data is being collected and how } \\
\text { it will be used }\end{array}$ \\
\hline 2 & $\begin{array}{l}\text { Accuracy and duration } \\
\text { of retention }\end{array}$ & $\begin{array}{l}\text { Personal data that has been collected should be kept accurate, up-to- } \\
\text { date and for no longer than is necessary }\end{array}$ \\
\hline 3 & Use & $\begin{array}{l}\text { Data must only be used for the specific or directly related purpose for } \\
\text { which it was collected. Any other use is conditional on consent of the } \\
\text { data subject }\end{array}$ \\
\hline 4 & Security & Suitable security measures should be applied to personal data \\
\hline 5 & Information availability & $\begin{array}{l}\begin{array}{l}\text { Data users should be open to the kind of data they store and what } \\
\text { they use it for }\end{array}\end{array}$ \\
\hline 6 & Access & $\begin{array}{l}\text { Data subjects have the right to access their personal data, to verify its } \\
\text { accuracy and to request correction }\end{array}$ \\
\hline
\end{tabular}

These principles are designed to enshrine the reasonable rights and duties of both the data subject (the person described by the data) and the data users (those who possess the data).

\section{eThekwini Municipality Environment}

The new Durban Metropolitan Unicity Municipality (DMUM) came into existence in the province of kwaZulu/Natal, South Africa following South Africa's second local government elections held in December 2000. Following Proclamation 343 (KwaZulu/Natal) dated 19 September 2000, DMUM has subsequently been renamed the eThekwini Municipality and comprises the former Durban Metropolitan Council (which includes the North Central and South Central Councils), the North Local Council, the South Local Council, the inner West City Council, the Outer West Local Council and the Umkomaas Transitional Local Council.2

eThekwini Municipality comprises six clusters/service units (Office of the City Manager, Treasury, Governance, Sustainable Development and City Enterprises, Corporate and Human Resources \& Health, Safety and Social Services) and employs approximately 22,000 employees. There are some 6,000 networked desktops (personal computers, thin clients and laptops) and electronic communication is via Novell's GroupWise (Client version 6.5). A total of 5,806 GroupWise accounts are in existence. There are approximately 1,500 Internet accounts utilising either Internet Explorer or Netscape Navigator web browsers. Given the magnitude of this ICT connectivity in terms of LANs and WANs and the potential for abuse and misuse of cybertechnology by employees, there is thus a need to formulate a Code of Cyberethics for eThekwini Municipality.

The proposed methodology for the formulation of the Code of Cyberethics is as follows:

- Disseminate the author's validated survey instrument (see Appendix A) to eThekwini Municipality employees who have Internet accounts;

- Qualitatively and quantitatively analyse the responses received to completed survey questionnaires. From the scored responses, themes, patterns and trends will be synthesized;

- Draft a proposed Code of Cyberethics based on eThekwini Municipality's (1) vision and mission; (2) moral and social values which the organisation wants reflected in all its activities; and (3) values that

2 For a discussion of ICT considerations in the eThekwini Municipality Area, see for example, Averweg \& Manyanga $(2003,2004)$. 
reflect characteristics of the organisation's approach to achieving its mission. Particular attention is to be paid to cybertechnology situations which appear to be genuinely problematic;

- Present the proposed Code of Cyberethics to eThekwini Municipality for ratification and adoption;

- Incorporate the document in the City Manager's Standing Orders and employees' Conditions of Service; and

- Utilise an appropriate and effective mechanism for communicating the adopted Code of Cyberethics to eThekwini Municipality employees.

Hanekom \& Thornhill (1987) note that a code of ethics normally has the objective of promoting and maintaining the responsible conduct of officials. McCabe, et al. (1996) found the existence of a corporate code of ethics was associated with significantly lower levels of self-reported unethical behaviour in the workplace. Ethics is not just about Codes - a code is only a small element of the process. Since eThekwini Municipality is about employees and structures (and not only documents), one needs to ensure that both employees and structures within which people operate support ethical practices. The author argues that the approach described above will underscore Kant's rule-based theory whereby the principle of an action that is being considered becomes the basis for everyone's action in eThekwini Municipality and all its employees will be willing to live in such a world as defined by the adopted Code of Cyberethics.

\section{Conclusion}

Chapman (1993) remarks that a code of conduct is necessary to assist public officials resolve ethical and value dilemmas and promote moral development. Cleek \& Leonard (1998) state that "emphasis should be placed on how the codes are communicated, enforced, and used, as a basis for strengthening the culture of the organization". McClenahen (1999) suggests that "being consistent in policies and actions, rewarding ethical conduct, treating employees fairly, and providing better executive leadership" work best to reduce unethical conduct. A commitment to the moral treatment of employees is one of the preconditions for continued excellence (Rossouw, 1994). Effective communication of the Code of Cyberethics to eThekwini Municipality employees can help eliminate situations wherein employees complain that they have not been made aware of corporate expectations regarding private Internet usage. Furthermore the development of a Code of Cyberethics will also ensure service delivery that responds effectively and efficiently to citizens' needs and improves the communication process with citizens.

In order to help the eThekwini Municipality create and maintain an environment conducive to ethical decision-making, a proposed statement of core values and a corporate Code of Cyberethics needs to be effectively communicated and supported by eThekwini Municipality management. In addition, enforcement processes need to support employees when they are faced with difficult dilemmas. In such an environment, an eThekwini Municipality employee should be less likely to reach an unethical decision due to the situational characteristics of a dilemma.

\section{Acknowledgement}

An earlier version of this paper was presented at Community Informatics Research Network Conference (CIRN2005), Cape Town, 23-26 August 2005.

\section{References}

Agranoff, M.H. (1993). Controlling the threat to personal privacy. Journal of Information Systems Management.

Andrews, Y. (1988). The personnel function. Pretoria: Haum.

Averweg, U.R. \& Manyanga, S.S.S. (2003, 8-10 December). ICT considerations for improving citizen service delivery and communications in a Metropolitan Municipality in South Africa. Proceedings of the World Forum on Information Society (WFIS), Geneva, Switzerland.

Averweg, U. \& Manyanga, S. (2004, 4-6 July). e-Government: ICT considerations for citizen service delivery and communication in a Metropolitan Municipality in South Africa. Proceedings of the 34th Southern Africa Computer Lecturers' Association (SACLA2004) Conference, Botha's Hill, KwaZulu-Natal, South Africa. 
Chapman, R.A. (ed.) (1993). Ethics in public service. London: Edinburgh University Press.

Charlesworth, M. \& Sewry, D.A. (2002). Ethical issues in enabling information technologies. Proceedings of the 2002 annual research conference of the South African Institute of Computer Scientists and Information Technologists, Port Elizabeth, South Africa, 163-171.

Cleek, M. \& Leonard, S. (1998, April). Can corporate codes of ethics influence behavior? Journal of Business Ethics, 619-630.

du Plessis, B. (ed.) (2004). Ethics in local government. Journal of the Institute of Municipal Finance Officers, 4(3), 16.

Gotterbarn, D. (1991). Computer ethics: Responsibility regained. National Forum: The Phi Kappa Phi Journal, 73(3), 26-31.

Hanekom, S.X. \& Thornhill, C. (1987) Public administration in contemporary society. Johannesburg: Macmillan South Africa Publishers.

Hoffman, W.M. \& Moore, J.M. (1990). Business ethics. New York: McGraw-Hill.

Johnson, D.G. (2001). Computer ethics (3rd ed.). Upper Saddle River, New Jersey: Prentice Hall.

Langford, D. (Ed.), (2000). Internet ethics. New York: St. Martin's Press.

Lending, D. \& Slaughter, S.A. (2001). Research in progress: the effects of ethical climate on attitudes and behaviors toward software piracy. Proceedings of the 2001 ACM SIGCPR Conference on Computer personnel research, 198-200.

Locke, J. (1964). Second treatise of civil government. New York: Bobbs-Merrill.

Mafunisa, M.J. (2000). Public service ethics. Kenwyn: Juta \& Co.

McCabe, D., Klebe Trevino, L. \& Butterfield, J. (1996). The influence of collegiate and corporate codes of conduct on ethics-related behavior in the workplace. Business Ethics Quarterly, 6(4), 461-470.

McClenahen, J. (1999, 1 March). Your employees know better. Industry Week, 12-13.

Rossouw, D. (1994). Business ethics: A South African perspective. Halfway House: Southern Book Publishers.

Russell, B. (1971). Human society in ethics and politics. London: George Allen \& Unwin Ltd.

Smith, H.J. (2002). Ethics and information systems: Resolving the quandaries. ACM SIGMIS Database, 33(3).

Spinello, R.A. (2003). CyberEthics: Morality and law in cyberspace (2nd ed.). Sudbury, MA: Jones and Barlett Publishers.

Steidlmeier, P. (1993). The moral legitimacy of intellectual property claims: American business and developing country perspectives. Journal of Business Ethics, 12(2), 157-164.

Sternberg, E. (1994). Just business: Business ethics in action. United Kingdom: Little Brown and Company.

Straub, D. \& Collins, R. (1990). Key information liability issues facing managers: Software piracy, proprietary databases, and individual rights to privacy. MIS Quarterly, 14(2), 143-156.

Sugden, R. (2003). Opportunity as a space for individuality: Its value and the impossibility of measuring it. Ethics, An International Journal of Social, Political, and Legal Philosophy, 113(4), 783-809.

Tavani, H.T. (2004). Ethics and technology: Ethical issues in an age of information and communication technology. Hoboken, New Jersey: John Wiley \& Sons.

Turban, E., McLean, E. \& Wetherbe, J. (2004). Information technology for management: Transforming organizations in the digital economy. Hoboken, New Jersey: John Wiley \& Sons. 


\section{Appendix A}

\section{Ethics Statement Survey for eThekwini Municipality Employees}

\section{Please indicate your Cluster/Service Unit}

Office of the City Manager

Treasury

Governance

Sustainable Development and City Enterprises

Corporate and Human Resources

Health, Safety and Social Services

Unsure

\section{Please indicate your gender}

Male

Female

Please indicate your level of agreement/disagreement with the following information and communication technology related statements. Answer all 12 questions.

\section{Strongly agree - Agree - Undecided - Disagree or Strongly disagree}

\section{I may copy someone else's software for my own personal use}

Strongly agree

Agree

Undecided

Disagree

Strongly disagree

Please tick any of the following factors that affected your answer (you may tick more than one)

I believe that the potential harm done to others would be minimal

I believe that most view this activity as acceptable

I believe that any harm that would take place would be to people I do not know

I believe the number of people harmed would be minimal

I believe that negative effects of this action would occur a very long time from now

I believe that the potential harm done to others would be high

I believe that most view this activity as wrong

I believe that any harm that would take place would be to people I know

I believe the number of people harmed would be high

I believe that negative effects of this action would occur very soon 


\section{I may distribute copies of someone else's software}

Strongly agree

Agree

Undecided

Disagree

Strongly disagree

Please tick any of the following factors that affected your answer (you may tick more than one)

I believe that the potential harm done to others would be minimal

I believe that most view this activity as acceptable

I believe that any harm that would take place would be to people I do not know

I believe the number of people harmed would be minimal

I believe that negative effects of this action would occur a very long time from now

I believe that the potential harm done to others would be high

I believe that most view this activity as wrong

I believe that any harm that would take place would be to people I know

I believe the number of people harmed would be high

I believe that negative effects of this action would occur very soon

\section{I may download music from the Internet for my own personal use}

Strongly agree

Agree

Undecided

Disagree

Strongly disagree

Please tick any of the following factors that affected your answer (you may tick more than one)

I believe that the potential harm done to others would be minimal

I believe that most view this activity as acceptable

I believe that any harm that would take place would be to people I do not know

I believe the number of people harmed would be minimal

I believe that negative effects of this action would occur a very long time from now

I believe that the potential harm done to others would be high

I believe that most view this activity as wrong

I believe that any harm that would take place would be to people I know

I believe the number of people harmed would be high

I believe that negative effects of this action would occur very soon

\section{I may distribute copies of downloaded music}

Strongly agree

Agree

Undecided 
Disagree

Strongly disagree

Please tick any of the following factors that affected your answer (you may tick more than one)

I believe that the potential harm done to others would be minimal

I believe that most view this activity as acceptable

I believe that any harm that would take place would be to people I do not know

I believe the number of people harmed would be minimal

I believe that negative effects of this action would occur a very long time from now

I believe that the potential harm done to others would be high

I believe that most view this activity as wrong

I believe that any harm that would take place would be to people I know

I believe the number of people harmed would be high

I believe that negative effects of this action would occur very soon

\section{I may download video from the Internet for my own personal use}

Strongly agree

Agree

Undecided

Disagree

Strongly disagree

Please tick any of the following factors that affected your answer (you may tick more than one)

I believe that the potential harm done to others would be minimal

I believe that most view this activity as acceptable

I believe that any harm that would take place would be to people I do not know

I believe the number of people harmed would be minimal

I believe that negative effects of this action would occur a very long time from now

I believe that the potential harm done to others would be high

I believe that most view this activity as wrong

I believe that any harm that would take place would be to people I know

I believe the number of people harmed would be high

I believe that negative effects of this action would occur very soon

\section{I may distribute copies of downloaded video}

Strongly agree

Agree

Undecided

Disagree

Strongly disagree 
Please tick any of the following factors that affected your answer (you may tick more than one)

I believe that the potential harm done to others would be minimal

I believe that most view this activity as acceptable

I believe that any harm that would take place would be to people I do not know

I believe the number of people harmed would be minimal

I believe that negative effects of this action would occur a very long time from now

I believe that the potential harm done to others would be high

I believe that most view this activity as wrong

I believe that any harm that would take place would be to people I know

I believe the number of people harmed would be high

I believe that negative effects of this action would occur very soon

\section{I may access private and confidential information without consent}

Strongly agree

Agree

Undecided

Disagree

Strongly disagree

Please tick any of the following factors that affected your answer (you may tick more than one)

I believe that the potential harm done to others would be minimal

I believe that most view this activity as acceptable

I believe that any harm that would take place would be to people I do not know

I believe the number of people harmed would be minimal

I believe that negative effects of this action would occur a very long time from now

I believe that the potential harm done to others would be high

I believe that most view this activity as wrong

I believe that any harm that would take place would be to people I know

I believe the number of people harmed would be high

I believe that negative effects of this action would occur very soon

\section{I may distribute private and confidential information without consent}

Strongly agree

Agree

Undecided

Disagree

Strongly disagree

Please tick any of the following factors that affected your answer (you may tick more than one) 
I believe that the potential harm done to others would be minimal

I believe that most view this activity as acceptable

I believe that any harm that would take place would be to people I do not know

I believe the number of people harmed would be minimal

I believe that negative effects of this action would occur a very long time from now

I believe that the potential harm done to others would be high

I believe that most view this activity as wrong

I believe that any harm that would take place would be to people I know

I believe the number of people harmed would be high

I believe that negative effects of this action would occur very soon

\title{
9. I may access other's desktops or laptops without consent
}

\author{
Strongly agree \\ Agree \\ Undecided \\ Disagree \\ Strongly disagree
}

Please tick any of the following factors that affected your answer (you may tick more than one)

I believe that the potential harm done to others would be minimal I believe that most view this activity as acceptable I believe that any harm that would take place would be to people I do not know I believe the number of people harmed would be minimal

I believe that negative effects of this action would occur a very long time from now I believe that the potential harm done to others would be high

I believe that most view this activity as wrong I believe that any harm that would take place would be to people I know I believe the number of people harmed would be high

I believe that negative effects of this action would occur very soon

\section{I may take programs or other work I have done for one employer and keep it for personal}

use

\author{
Strongly agree \\ Agree \\ Undecided \\ Disagree \\ Strongly disagree
}

Please tick any of the following factors that affected your answer (you may tick more than one)

I believe that the potential harm done to others would be minimal I believe that most view this activity as acceptable I believe that any harm that would take place would be to people I do not know I believe the number of people harmed would be minimal 
I believe that negative effects of this action would occur a very long time from now I believe that the potential harm done to others would be high

I believe that most view this activity as wrong

I believe that any harm that would take place would be to people I know

I believe the number of people harmed would be high

I believe that negative effects of this action would occur very soon

11. I may take programs or other work I have done for one employer and use it at another employer

Strongly agree
Agree
Undecided
Disagree
Strongly disagree

Please tick any of the following factors that affected your answer (you may tick more than one)

I believe that the potential harm done to others would be minimal

I believe that most view this activity as acceptable

I believe that any harm that would take place would be to people I do not know

I believe the number of people harmed would be minimal

I believe that negative effects of this action would occur a very long time from now

I believe that the potential harm done to others would be high

I believe that most view this activity as wrong

I believe that any harm that would take place would be to people I know

I believe the number of people harmed would be high

I believe that negative effects of this action would occur very soon

\section{At work, I do not have to correct inaccurate information I may hold about customers}

Strongly agree

Agree

Undecided

Disagree

Strongly disagree

Please tick any of the following factors that affected your answer (you may tick more than one)

I believe that the potential harm done to others would be minimal

I believe that most view this activity as acceptable

I believe that any harm that would take place would be to people I do not know

I believe the number of people harmed would be minimal

I believe that negative effects of this action would occur a very long time from now

I believe that the potential harm done to others would be high

I believe that most view this activity as wrong

I believe that any harm that would take place would be to people I know

I believe the number of people harmed would be high 


\section{I believe that negative effects of this action would occur very soon}

(Acknowledgement: This instrument is an adapted version of the Ethics Statement Survey developed by Alan Peslak, Penn State University, Dunmore, PA, USA. Retrieved on 21 October, 2005 from http://wsistdevel.sn.psu.edu/ist/arp14/eths1/webform1.aspx ) 